\title{
Histamine- and insulin-stimulated gastric acid secretion after selective and truncal vagotomy
}

\author{
S. BANK, I. N. MARKS, AND J. H. LOUW \\ From the Gastro-Intestinal Service, Groote Schuur Hospital, and the Departments of Medicine and Surgery, \\ University of Cape Town, Observatory, Cape Town, South Africa
}

EDITORIAL COMMENT The mean percentage acid reduction after selective vagotomy is of the same order as after truncal vagotomy.

Histamine- and insulin-stimulated gastric secretion after vagotomy has been the subject of a number of papers in recent years (Weinstein, Hollander, Lauber, and Colp, 1950; Gelb, Baronofsky, and Janowitz, 1961 ; Kyle and Stephens, 1961 ; Payne and Kay, 1962; Austen and Edwards, 1961). Most workers agree that truncal vagotomy associated with a drainage procedure is followed, in the vast majority of patients by an appreciable reduction in the level of acid secretion (Gillespie, Clark, Kay, and Tankel, 1960; Gelb et al., 1961; Bell, 1964). Selective vagotomy, a procedure championed by Burge (1960), has been employed with success by a number of surgeons in recent years but no data are as yet available regarding its efficacy in reducing acid secretion.

The purpose of this paper is to re-evaluate gastric acid secretory function after vagotomy and to compare the results obtained after selective and truncal vagotomy. In addition the relationship between insulin- and histamine-stimulated secretion after vagotomy will be presented and the interpretation of the insulin test reviewed.

\section{MATERIAL}

Gastric acid secretion was studied by means of the augmented histamine test in 136 consecutive patients before and after an abdominal vagotomy combined with a drainage procedure. The number of patients in whom a

TABLE I

\begin{tabular}{|c|c|c|c|}
\hline & $\begin{array}{l}\text { With } \\
\text { Pyloroplasty }\end{array}$ & $\begin{array}{l}\text { With } \\
\text { Gastroenterostomy }\end{array}$ & Total \\
\hline $\begin{array}{l}\text { Selective vagotomy } \\
\text { Truncal vagotomy } \\
\text { Total }\end{array}$ & $\begin{array}{l}47 \\
30 \\
77\end{array}$ & $\begin{array}{r}5 \\
54 \\
59\end{array}$ & $\begin{array}{r}52 \\
84 \\
136\end{array}$ \\
\hline
\end{tabular}

selective or truncal vagotomy was done and the type of drainage procedure carried out are shown in Table $I$.

Selective vagotomy implied preservation of the hepatic branch of the anterior vagus and the coeliac branch of the posterior vagus in the majority of cases. A few patients had an anterior selective vagotomy only. The gastroenterostomy was retrocolic in 54 of the 59 patients; the remaining five were antecolic and juxtapyloric.

The gastric acid secretory response to insulin was determined routinely in 60 of the 136 patients after vagotomy. Of these 60 patients, 20 had a selective vagotomy, and 40 a truncal vagotomy. In addition, a further three patients referred directly for symptoms of recurrent jejunal ulceration were included in the comparison of the insulin response and post-vagotomy histamine secretion. No pre-operative acid studies were available in them.

\section{METHODS}

THE AUGMENTED HISTAMINE TEST (KAY, 1953; MARKS, BANK, LOUW, AND VAN EMBDEN, 1962) A radioopaque nasogastric tube was positioned into the dependent part of the stomach under fluoroscopic control, and the fasting gastric juice aspirated. Anthisan, $50 \mathrm{mg}$. intramuscularly, was given midway through the basal hour collection and histamine acid phosphate, 0.04 mg. $/ \mathrm{kg}$. intramuscularly, at the start of the histamine hour. Aliquots of the basal and post-histamine collections were titrated with $\mathrm{N} / 10 \mathrm{NaOH}$ using Töpfer's reagent and phenophthalein as indicators for 'free' and 'total' acid respectively. For the purpose of this paper only the total acid output per hour for the basal (B.S.) and post-histamine response (M.A.O.) will be considered. Absolute achlorhydria was regarded as a failure of the $p \mathrm{H}$ to fall below 6 after maximal histamine stimulation, and an arbitrary M.A.O. value of $0.1 \mathrm{mEq}$./hour was used to designate a fall in $p \mathrm{H}$ between 3.5 and 6 .

The pre-operative histamine test was carried out at a variable period before surgery and the test repeated within two months post-operatively. The post-operative 
augmented histamine test was repeated after a few weeks in those patients in whom the result within the first 14 days following vagotomy showed either virtual achlorhydria or an M.A.O. in excess of $50 \%$ of the preoperative post-histamine response. There were two patients in whom the former and four in whom the latter occurred. The result of the second post-operative augmented histamine test was used in the analysis of the data in these six patients.

THE INSULIN TEST A modification of Hollander's (1948) insulin test was used. The fasting patients were intubated and the radio-opaque nasogastric tube was positioned fluoroscopically into the stomach. The fasting gastric juice was aspirated, noted, and discarded. Basal secretion was collected for two 30-minute periods and this was followed by four 30-minute collections after the intravenous injection of 15 to 20 units of soluble insulin. Aliquots of the 30-minute collections were titrated with $\mathrm{N} / 10 \mathrm{NaOH}$ using Töpfer's reagent and phenophthalein as indicators for free and total acid. The volume, $p \mathrm{H}$, acid concentration, and acid output of each sample were measured.

INTERPRETATION A positive response to insulin, conventionally regarded as a measure of incomplete vagotomy, was taken as a rise in free acid concentration of more than $20 \mathrm{mEq}$./1. of the basal secretion and more than $10 \mathrm{mEq}$./1. if no basal secretion was present, in any 30-minute period of the test. These results were compared with the pre- and post-operative augmented histamine test.

Because of the almost universal dissatisfaction with the Hollander criteria for completeness of vagotomy, however (Woodward, Harper, Tovee, and Dragstedt, 1949; Bachrach, 1962), a group of other parameters reported as indicative of a positive insulin response was also considered in relation to the results of the augmented histamine test. These criteria were: (1) a rise in volume after insulin (Waddell, 1957); (2) a basal secretion greater than $2 \mathrm{mEq}$./hour (Bachrach, 1962); (3) a rise in free acid concentration greater than $20 \mathrm{mEq} . / \mathrm{l}$. (as above) (Hollander, 1948); (4) an 'early' rise (Ross and Kay, 1964) in free acid concentration, i.e., a response in the first hour after insulin; and (5) a rise in 'free' or 'total' acid output greater than $1.5 \mathrm{mEq}$./hour or $2 \mathrm{mEq}$./hour respectively in any one hour after insulin (Bank and
Marks, 1966). These criteria have been designated from 1 plus $(+)$ to 5 plus $(+++++)$ depending on how many of the parameters were present after insulin, and are referred to as 'multiple criteria'.

\section{RESULTS IN THE AUGMENTED HISTAMINE TEST}

EFFECT OF TYPE OF VAGOTOMY ON ACID SECRETION Table II shows the mean values and standard deviations and the mean parcentage reduction in the basal acid secretion and M.A.O. before and after vagotomy in the 136 patients. In addition, it compares the results found in 52 patients who had a selective vagotomy with the 84 patients who had a truncal vagotomy.

The mean percentage reduction for basal secretion was 64 and for the M.A.O. 71 in the 136 patients. There was no significant difference between selective and truncal vagotomy with regard to both the absolute values $(P>0.5)$ and percentage reduction in acid secretion $(P>0.5)$. However, the mean percentage reduction in acid secretion was slightly greater in the selective group.

EFFECT OF TYPE OF DRAINAGE PROCEDURE ON ACID SECRETION Table II also shows the mean values and standard deviation and the percentage reduction in basal acid secretion and M.A.O. before and after the drainage procedures. In addition, it compares the values found in 77 patients who had a pyloroplasty with the 59 who had a gastroenterostomy. The mean percentage reduction for basal secretion was 65 and for the M.A.O. 71 in the 136 patients. There was no significant difference between the two drainage procedures with regard to the ensuing reduction in both basal secretion (P>0.5) and M.A.O. $(P>0.5)$. However, the mean percentage reduction in basal acid secretion was only 58 after gastroenterostomy compared with 70 for pyloroplasty. This held true whether the drainage procedure was combined with a selective or truncal vagotomy. Five patients who had a truncal vagotomy and gastroenterostomy were completely achlorhydric on repeated testing. The

TABLE II

BASAL ACID SECRETION AND M.A.O. BEFORE AND AFTER SELECTIVE OR TRUNCAL VAGOTOMY, PYLOROPLASTY, OR GASTROENTEROSTOMY

Basal Acid Output (mEq. total acid/hour) M.A.O. (mEq. total acid/hour)

\begin{tabular}{|c|c|c|c|c|c|c|c|}
\hline \multirow[b]{2}{*}{ Operation } & \multirow[b]{2}{*}{$\begin{array}{l}\text { No of } \\
\text { Patients }\end{array}$} & \\
\hline & & $\begin{array}{l}\text { Pre-operative } \\
\text { Mean } \pm S D\end{array}$ & $\begin{array}{l}\text { Post-operative } \\
\text { Mean } \pm S D\end{array}$ & $\begin{array}{l}\text { Percentage } \\
\text { Reduction } \\
\text { after Operation } \boldsymbol{N}\end{array}$ & $\begin{array}{l}\text { Pre-operative } \\
\text { Mean } \pm S D\end{array}$ & $\begin{array}{l}\text { Post-operative } \\
\text { Mean } \pm S D\end{array}$ & $\begin{array}{l}\text { Percentage } \\
\text { Reduction } \\
\text { after Operation }\end{array}$ \\
\hline $\begin{array}{l}\text { Selective } \\
\text { Truncal } \\
\text { Total }\end{array}$ & $\begin{array}{r}52 \\
84 \\
136\end{array}$ & $\begin{array}{l}5 \cdot 6 \pm 5 \cdot 4 \\
4 \cdot 7 \pm 3 \cdot 7\end{array}$ & $\begin{array}{r}1.9 \pm 2.1 \\
1.8 \pm 1.9 \\
-\end{array}$ & $\begin{array}{l}66 \\
62 \\
64\end{array}$ & $\begin{array}{l}28 \cdot 5 \pm 12.9 \\
28.3 \pm 9.6\end{array}$ & $\begin{array}{l}7 \cdot 8 \pm 5 \cdot 9 \\
8 \cdot 5 \pm 9 \cdot 2\end{array}$ & $\begin{array}{l}73 \\
70 \\
71\end{array}$ \\
\hline $\begin{array}{l}\text { Pyloroplasty } \\
\text { Gastroenterostomy } \\
\text { Total }\end{array}$ & $\begin{array}{r}77 \\
59 \\
136\end{array}$ & $\begin{array}{l}5 \cdot 3 \pm 4 \cdot 7 \\
5 \cdot 0 \pm 3 \cdot 6\end{array}$ & $\begin{array}{l}1 \cdot 6 \pm 2 \cdot 1 \\
2 \cdot 1 \pm 3 \cdot 7\end{array}$ & $\begin{array}{l}70 \\
58 \\
65\end{array}$ & $\begin{array}{l}27.4 \pm 12.3 \\
29.6 \pm 8.8\end{array}$ & $\begin{array}{l}8 \cdot 1 \pm 6 \cdot 4 \\
8 \cdot 5 \pm 9 \cdot 9\end{array}$ & $\begin{array}{l}70 \\
72 \\
71\end{array}$ \\
\hline
\end{tabular}


latter was not found in any of the patients in whom pyloroplasty had been carried out.

THE INSULIN TEST Seventeen of the 60 patients on whom routine insulin tests were done had a 'positive' Hollander-type response. Four of the 17 patients had had a selective vagotomy and the remaining 13 a truncal vagotomy. The overall incidence of positive insulin responses in this series was thus $28 \%$, the incidence for selective vagotomy being $20 \%$ and for truncal vagotomy $32 \%$.

RELATIONSHIP BETWEEN INSULIN- AND HISTAMINESTIMULATED ACID SECRETION AFTER VAGOTOMY

COMPARISON OF M.A.O. VALUES IN POSITIVE AND NEGATIVE INSULIN TESTS Figure 1 compares the postvagotomy M.A.O. values with a positive or negative response to insulin in the 60 patients subjected to routine insulin tests and also in three patients tested specifically for symptoms of jejunal ulceration. The latter three patients had 'positive' insulin tests. A value for M.A.O. greater than $19 \mathrm{mEq}$./hour was found in seven $(35 \%)$ of the 20 patients with a positive response to insulin and only one $(2.3 \%)$ of the 43 patients with a negative insulin response. This patient had had a porto-caval anastomosis for cirrhosis at the time of the vagotomy and pyloroplasty procedure and subsequently developed a gastric ulcer. Conversely, a value for M.A.O. less than $3 \mathrm{mEq}$./hour was not found in any of the patients with a positive insulin response but occurred in eight $(19 \%)$ of the 43 with a negative test. The mean M.A.O. in the negative insulin response group was $8.3 \mathrm{mEq}$./hour, and in the positive insulin response group $17.8 \mathrm{mEq}$./hour. This difference was significant $(\mathrm{P}<0.001)$.

PERCENTAGE M.A.O. REDUCTION IN POSITIVE AND NEGATIVE INSULIN TESTS Pre- and post-operative values for M.A.O. were available in the 60 patients on whom a routine insulin test was done. Of these, 17 had a positive response to insulin and 43 a negative response. The mean percentage M.A.O. reduction after vagotomy was 53 in patients with a positive insulin response and 73 in those patients with a negative response.

The percentage reduction in M.A.O. was further analysed in relation to the time after the insulin was given in the 17 patients with a positive insulin response. Twelve patients had a positive response in the first hour and five had a positive response in the second hour only. The mean percentage reduction in M.A.O. was 49 and 61 respectively.

PERCENTAGE M.A.O. REDUCTION IN RELATION TO MULTIPLE CRITERIA OF POSITIVE OR NEGATIVE INSULIN TESTS The results of the 60 insulin tests were

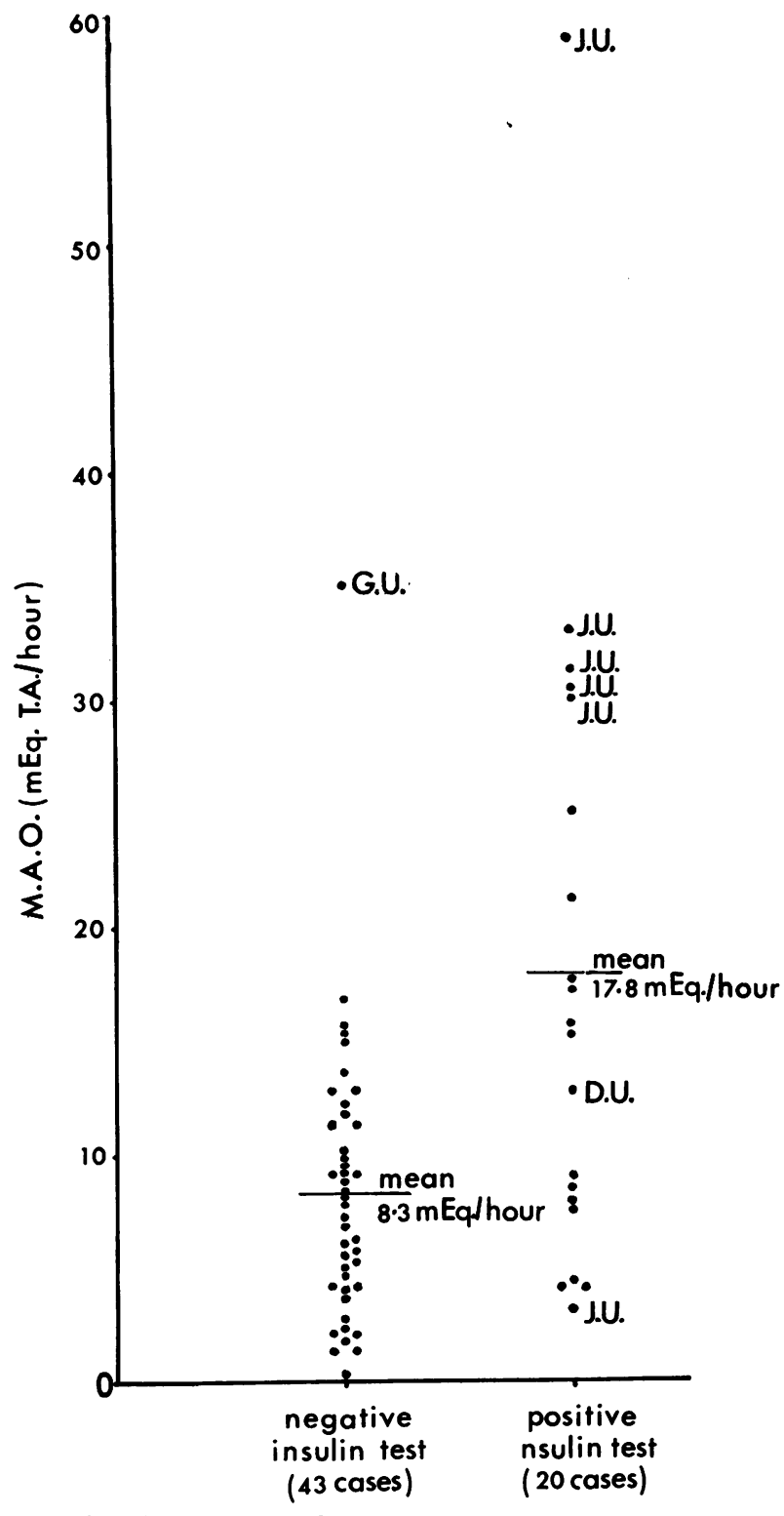

FIG. 1. Comparison of post-vagotomy M.A.O. values with a positive or negative Hollander-type response to insulin.

T.A. = total acid, M.A.O. = maximum acid output, J.U. = recurrent jejunal ulcer, D.U. = recurrent duodenal ulcer, G.U. = gastric ulcer.

further expressed in terms of the number of parameters of positive response to insulin as described in methods. There were 22 patients in whom the test was negative on all criteria, 18 in whom an elevated basal secretion was the only abnormality, and a further five in whom one of the remaining 


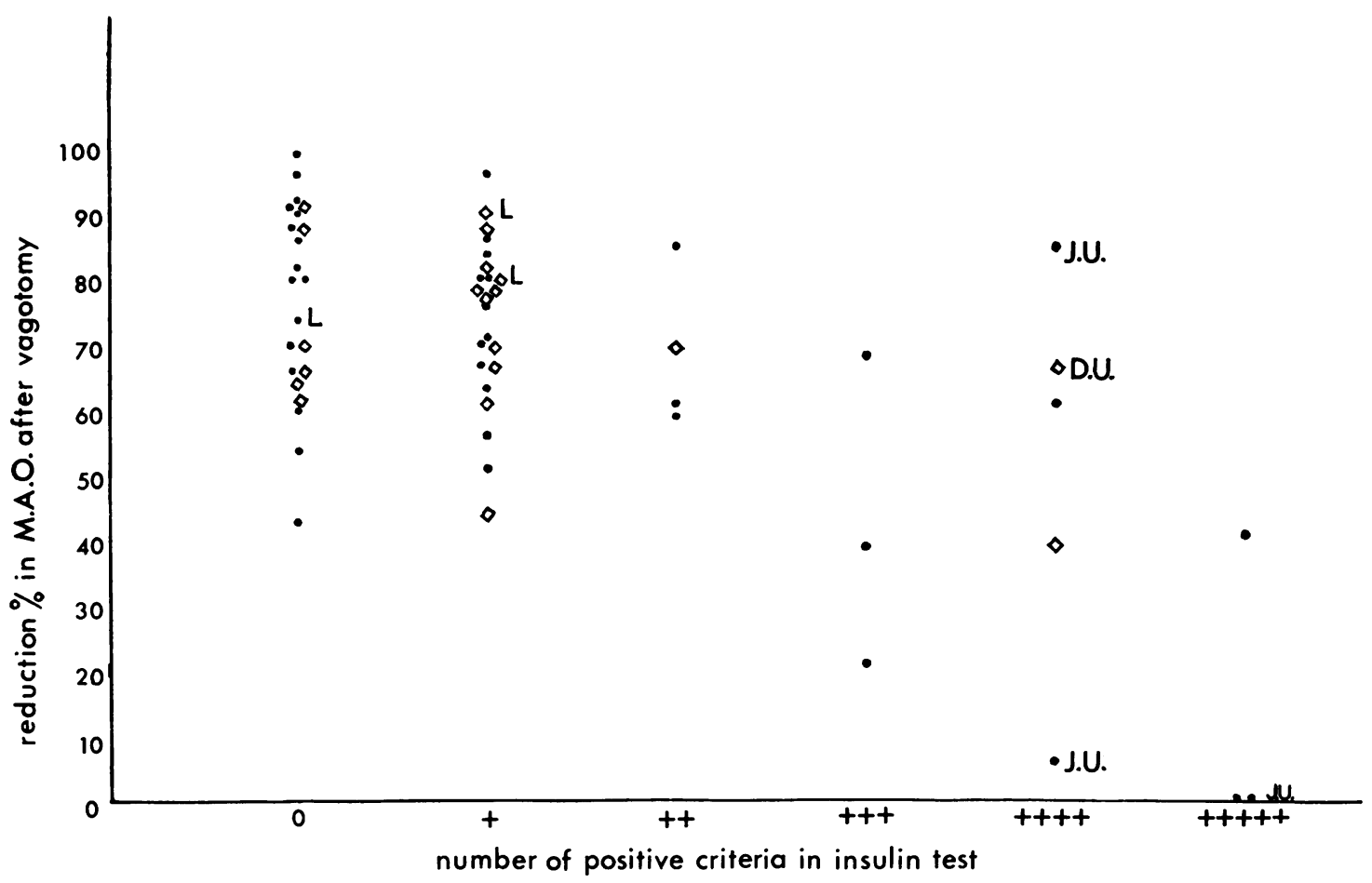

FIG. 2. Percentage M.A.O. reduction in relation to number of criteria of positivity in insulin test when 'multiple criteria' were used.

J.U. = recurrent jejunal ulcer, D.U. = recurrent duodenal ulcer, L. = negative laparotomy. $=$ truncal vagotomy, $\diamond=$ selective vagotomy.

parameters was the sole abnormality. Four patients had two positive parameters, three had three positive parameters, and five had four positive parameters. The remaining three patients were positive on all five criteria. The results in these patients were plotted against the percentage reduction in M.A.O. as shown in Figure 2. Seven of the 11 patients with three or more positive criteria had a mean percentage reduction in M.A.O. less than 50 as compared with two of 49 patients with less than three positive criteria. When four or more positive criteria were considered, five of eight patients showed a mean M.A.O. reduction less than $50 \%$. All the patients with proven recurrent duodenal or jejunal ulceration showed four or more positive criteria, but two of these patients showed only a slight or moderate reduction in M.A.O. Using multiple criteria, $10 \%$ of patients with selective vagotomies had four or more positive criteria as against $20 \%$ for truncal vagotomy.

RELATIONSHIP BETWEEN INSULIN TEST AND PERCENTAGE M.A.O. REDUCTION TO RECURRENT ULCERATION Table III shows the results of the modified Hollander test and percentage M.A.O. reduction in seven
TABLE III

INSULIN TEST AND PERCENTAGE M.A.O. REDUCTION IN SEVEN PATIENTS WITH PROVED RECURRENT ULCERATION AFTER VAGOTOMY

\begin{tabular}{|c|c|c|}
\hline Insulin Test & Present & Absent \\
\hline dified Hollander test & 7 & $\mathbf{0}$ \\
\hline Positive insulin response in first hour & 6 & 1 \\
\hline $\begin{array}{l}\text { Four or five positive multiple criteria of insulin } \\
\text { test } \\
\text { M.A.O. }\end{array}$ & 7 & 0 \\
\hline $\begin{array}{l}\text { Reduced by } 60 \% \text { or more } \\
{ }^{1} \text { Three patients referred specifically for sy }\end{array}$ & $2^{1}$ & 2 \\
\hline
\end{tabular}

TABLE IV

COMPARISON BETWEEN MODIFIED HOLLANDER TEST, POSITIVE INSULIN RESPONSE IN FIRST HOUR, AND FOUR OR FIVE MULTIPLE CRITERIA OF INSULIN TEST IN RELATION TO RECURRENT ULCERATION AND DYSPEPSIA AFTER VAGOTOMY Insulin Test Positive Proved Ulcer Free of Negative $\begin{array}{llll}\text { Proved } & \text { Ulcer } & \text { Free of } & \text { Negative } \\ \text { Jejunal } & \text { Dyspepsia } & \text { Symptoms } & \text { with } \\ \text { Ulcer } & \text { Recurrent } & \text { Jejunal } \\ & \text { Ulcer } & \text { Ulcer }\end{array}$ Not Proven

\begin{tabular}{|c|c|c|c|c|c|}
\hline \multirow[t]{3}{*}{$\begin{array}{l}\text { Positive modified } \\
\text { Hollander test } \\
\text { Positive insulin }\end{array}$} & 17 & 4 & 2 & 11 & 0 \\
\hline & 12 & 3 & 2 & 6 & 1 \\
\hline & 8 & 4 & 2 & 2 & 0 \\
\hline
\end{tabular}


patients with recurrent ulceration after vagotomy. All seven patients had a positive modified Hollander test and at least four of the positive multiple criteria. On the other hand, the positive response to insulin was 'late' in one of the seven patients and a marked reduction in M.A.O., viz., $66 \%$ and $85 \%$ respectively, was noted in a further two. Table IV is included to show that of the 17 patients with a positive Hollander test, 12 had positive responses in the first hour while only eight had at least four of the positive multiple criteria. Eleven $(64 \%)$ of the 17 patients with a positive Hollander test are free of symptoms after a four year follow-up compared with two $(25 \%)$ of eight who showed multiple positive criteria on the insulin test.

Three of 45 patients with less than two positive criteria continued to be troubled by persistent dyspepsia post-operatively. Laparotomy and repyloroplasty in these three patients showed no evidence of recurrent ulceration.

\section{DISCUSSION}

The mean percentage reduction in basal and histamine-stimulated gastric acid secretion after vagotomy in this series of $64 \%$ and $71 \%$ respectively was virtually identical to that reported following truncal vagotomy by previous workers (Gillespie et al., 1960; Gelb et al., 1961; Ross and Kay, 1964; Bell, 1964). Our data, however, were derived from a mixed group of patients who had had selective and truncal vagotomies. The present study showed that the mean percentage acid reduction after selective vagotomy was of the same order as after truncal vagotomy.

Our experience with a slight modification of Hollander's test for vagal integrity has shown a $28 \%$ incidence of positive responses to insulin. The percentage of alleged incomplete vagotomies is in accord with the collected data of Ross and Kay (1964) who reported a mean incidence of $31 \%$ positive insulin responses. Based on the Hollander criteria the patients who had a selective vagotomy fared somewhat better than those in whom a truncal vagotomy was done: the incidence of positive tests was $20 \%$ in the selective group as against $32 \%$ in the truncal group. It should be noted, however, that the selective vagotomies were carried out by one or two senior surgeons and that truncal vagotomies were done by a number of surgeons and registrars on the staff. Despite this, the data on the postvagotomy histamine and insulin tests permit the conclusion to be drawn that selective vagotomy is at least as effective as truncal vagotomy in reducing the level of gastric acid secretion.

An analysis of the relationship between the insulin test and the post-vagotomy M.A.O. showed that patients who had a positive insulin response had a significantly higher M.A.O. than patients with a negative insulin response. With the exception of one patient who had a porto-caval anastomosis at the time of vagotomy, all the patients with a negative insulin response had an M.A.O. value less than $19 \mathrm{mEq}$./hour, whereas the patients with a positive insulin test exceeded this figure in $32 \%$ of cases. In addition, the lowest value for M.A.O. found in patients with a positive insulin response was $3 \mathrm{mEq}$./hour while values lower than this were not uncommon in patients with a negative test. A postvagotomy value for M.A.O. exceeding $19 \mathrm{mEq}$./hour was therefore very suggestive of an incomplete vagotomy, and a value less than $3 \mathrm{mEq}$./hour was a pointer towards completeness of vagotomy when assessed by Hollander's criteria. When considered in terms of mean percentage reduction in M.A.O. it was found that patients with a negative insulin test had a mean percentage reduction of 73 compared with 53 in those with a positive response.

When these data for patients with a positive test were analysed according to the time after the administration of insulin, the mean M.A.O. reduction was $49 \%$ in those who had an 'early' response in the first hour after insulin and $61 \%$ in those who had a 'late' response in the second hour after insulin. Ross and Kay (1964), who had previously drawn attention to the possible value of this type of analysis in the diagnosis of ulceration, reported that patients with an 'early' response showed only a $9 \%$ reduction in M.A.O., a figure that may be construed as being at variance with the $49 \%$ reduction in the present series. Possible factors accounting for the discrepancy include the following. In calculating the mean M.A.O. reduction, a post-operative M.A.O. exceeding the pre-operative M.A.O. was designated as $0 \%$ acid reduction in the present study but as a minus value by Ross and Kay. In the present study, an acid secretory response within one hour of the insulin was used as a measure of an early response whereas Ross and Kay regarded an early response as occurring within 45 minutes of the administration of insulin. General dissatisfaction with the Hollander test (Woodward et al., 1949; Bachrach, 1962; Stempien, 1962) as an index of incomplete vagotomy in man has prompted many workers to seek alternative criteria. Ross and Kay's (1964) data indicate that the 'early' response to insulin and a poor reduction in M.A.O. may be of greater value in sorting out those patients at risk of recurrent ulceration than the Hollander criteria. While this general trend was confirmed in the present study, the finding of a distinct later response to insulin in one of our patients with recurrent ulceration and an 
$85 \%$ reduction in M.A.O. in another prompted us to assess the value of combining a number of criteria which have been put forward by various workers as an index of the completeness of vagotomy. Five parameters were employed. These comprised the level of basal secretion (Bachrach, 1962), a rise in volume (Waddell, 1957), a rise in acid concentration (Hollander, 1948), an early rise in acid concentration (Ross and Kay, 1964), and a rise in acid output in any one hour of the insulin test (Bank and Marks, 1966). Eight patients in the present series had at least four of the five multiple criteria and four of them had already developed surgically proved recurrent ulcers. Although the four patients with recurrent ulceration also had a positive test, using Hollander's conventional criteria of incomplete vagotomy, a further 11 also showed a positive Hollander test and are in good health after follow-up for four years. We are tempted to agree with Ross and Kay that a positive Hollander test alone may be found despite a surgically and, indeed, physiologically adequate vagotomy, and it is suggested that a combination of criteria of the insulin test may be a more accurate method of assessing the true incidence of incomplete vagotomies.

Although the insulin test has been condemned by a number of workers, the importance of having some measure of an incomplete vagotomy in a patient with dyspepsia after a vagotomy has been highlighted by the difficulty in the radiological demonstration of a recurrent duodenal ulcer after pyloroplasty.

A comparison between the types of drainage procedure showed no significant difference in acid secretion after pyloroplasty or gastroenterostomy, for both basal secretion and M.A.O. However, the mean percentage reduction in basal acid secretion was lower after gastroenterostomy than after pyloroplasty. The tendency for basal secretion after gastroenterostomy to be somewhat higher might be due to antral alkalinization and gastrin release resulting from regurgitation of bile.

\section{SUMMARY}

Augmented histamine tests were carried out in a series of 136 patients before and after selective or truncal vagotomy combined with a drainage procedure. The mean percentage reduction in basal secretion and the M.A.O. was 64 and 71 respectively in the 136 patients and there was no significant difference between the results in patients following the two types of vagotomy.

A modified Hollander test carried out in 60 of the
136 patients showed a $28 \%$ incidence of positive responses, the incidence in the selective vagotomy being slightly lower than in the total vagotomy group.

The post-operative results for the augmented histamine test and the percentage reduction in M.A.O. were correlated with the results of the Hollander test.

The use of five 'multiple criteria' in the assessment of an insulin test response was suggested in an attempt to help define those patients at risk of recurrent ulceration.

This study was supported by the Ben May Gastroenterology Research Fund, the South African Council for Scientific and Industrial Research, and the Hermann Bequest.

We thank the Medical Superintendent (Dr. J. G. Burger) for permission to publish, and the surgeons on the staff of Groote Schuur Hospital for their support.

\section{REFERENCES}

Austen, W. G., and Edwards, H.C. (1961). A clinical appraisal of the treatment of chronic duodenal ulcer by vagotomy and gastric drainage procedure. Gut, 2, 158-162.

Bachrach, W. H. (1962). Laboratory criteria for the completeness of vagotomy. Amer. J. dig. Dis., 7, 1071-1085.

Bank, S., and Marks, I. N. (1966). Unpublished data.

Bell, P. R. F. (1964). The long term effect of vagotomy on the maximal acid response to histamine in man. Gastroenterology, 46, 387-391.

Burge, H. W. (1960). Vagotomy in the treatment of peptic ulceration. Postgrad. med. J., 36, 2-12.

Gelb, A. M., Baronofsky, I. D., and Janowitz, H. D. (1961). The effect of vagotomy and pyloroplasty on the maximal acid response to histamine. Gut, 2, 240-245.

Gillespie, I. E., Clark, D. H., Kay, A. W., and Tankel, H. I. (1960) Effect of antrectomy, vagotomy with gastrojejunostomy, and antrectomy with vagotomy on the spontaneous and maximal gastric acid output in man. Gastroenterology, 38, 361-367.

Hollander, F. (1948). Laboratory procedures in the study of vagotomy (with particular reference to the insulin test). Gastroenterology, 11, 419-425.

Kay, A. W. (1953). Effect of large doses of histamine on gastric secretion of $\mathrm{HCl}$ : an augmented histamine test. Brit. med. J., 2, 77-80.

Kyle, J., and Stephens, F. (1961). Gastric acidity after duodenal ulcer surgery. (Abstr.), Brit. J. Surg., 48, 465.

Marks, I. N., Bank, S., Louw, J. H., and Van Embden, B. H. (1962). The augmented histamine test. An analysis of 672 consecutive tests. S.Afr, med. J., 36, 807-812.

Payne, R. A., and Kay, A. W. (1962). The effect of vagotomy on the maximal acid secretory response to histamine in man. Clin. Sci., 22, 373-382.

Ross, B., and Kay, A. W. (1964). The insulin test after vagotomy. Gastroenterology, 46, 379-386.

Stempien, S. J. (1962). Insulin gastric analysis: technic and interpretations. Amer. J. dig. Dis., 7, 138-152.

Waddell, W. R. (1957). The acid secretory response to histamine and insulin hypoglycemia after various operations on the stomach. Surgery, 42, 652-658.

Weinstein, V. A., Hollander, F., Lauber, F. U., and Colp, R. (1950), Correlation of insulin test studies and clinical results in a series of peptic ulcer cases treated by vagotomy. Gastroenterology, 14, 214-227.

Woodward, E. R., Harper, P. V., Jr., Tovee, E. B., and Dragstedt L. R. (1949). Effect of vagotomy on gastric secretion in man and experimental animals. Arch. Surg., 59, 1191-1212. 